\title{
PENGELOLAAN PENGADUAN PELAYANAN MASYARAKAT PADA DINAS PENANAMAN MODAL DAN PELAYANAN TERPADU SATU PINTU KOTA BANJARMASIN
}

\author{
Firdaus ${ }^{1}$ Irawanto $^{2}$ \\ 1,2 Program Pascasarjana STIA Bina Banua Banjarmasin \\ e-mail: firdauskla79@gmail.com; irawanto67@gmail.com
}

\begin{abstract}
Abstrak: Penelitian ini bertujuan untuk menganalisa mekanisme, alur pengelolaan pengaduan dan mengidentifikasi kendala yang dihadapi dalam pengelolaan pengaduan pelayanan masyarakat. Pendekatan penelitan dilakukan dengan deskriftif kualitatif. Data penelitian diperoleh dari sumber informasi dan sumber informasi kunci. Teknik pengumpulan data dilakukan dengan wawancara, observasi dan dokumentasi, data hasil penelitian dianalisa dengan langkah reduksi data, penyajian data dan pengambilan kesimpulan/verifikasi. Hasil penelitian menunjukkan Mekanisme dan alur pengaduan pada Dinas Penanaman Modal dan Pelayanan Terpadu Satu Pintu Kota Banjarmasin tidak sesuai dengan Permen PAN RB No. 24/2014. Kedua, Ada 2 (dua) faktor yang menjadi kendala dalam pengelolaan pengaduan pelayanan masyarakat yaitu; a) faktor internal, yaitu kurangnya jumlah orang dan kompetensi petugas b) faktor eksternal yaitu kurangnya pengetahuan masyarakat karena kurangnya sosialisasi terkait materi aduan yang tidak sesuai dengan tugas dan fungsi dinas ini.
\end{abstract}

Kata Kunci: Pengelolaan; Pelayanan Publik; Pengaduan Masyarakat

Abstract: This study aims to analyze the mechanisms, flow of complaints management and identify the obstacles faced in managing public service complaints. The research approach was carried out with a qualitative descriptive approach. Research data were obtained from sources of information and key sources of information. The technique of collecting data was carried out by observation, interviews and documentation, the research data were analyzed using data reduction, data presentation and conclusion / verification. The results showed that the complaint mechanism and flow at the Banjarmasin Investment Agency and One Stop Integrated Service were not in accordance with the PAN RB Regulation No. 24/2014. Second, there are 2 (two) factors that become obstacles in the management of public service complaints, namely; a) internal factors, namely the lack of the number of people and the competence of officers $b$ ) external factors, namely the lack of public knowledge due to the lack of socialization regarding complaint material that is not in accordance with the duties and functions of this agency.

Keywords: Management; Public Services; Community Complaints

\section{PENDAHULUAN}

Instansi pemerintah terkait pelayanan publik salah satunya adalah Dinas Penanaman Modal dan Pelayanan Terpadu Satu Pintu (DPMPTS) Kota Banjarmasin, yang memberikan pelayanan selaku abdi Negara dan abdi masyarakat sebagian belum berjalan secara optimal karena mutu pelayanan yang menyangkut prosedur, waktu penyelesaian, biaya maupun persyaratan yang ada kompetensi pegawai, keramahan petugas serta sarana dan prasarana saat 
itu belum optimal, untuk itu harus ada perbaikan sistem pelayanan terutama perizinan dan non perizinan yang ada.

Kurang puasnya pelayanan publik yang diterima oleh masyarakat membuat masyarakat melakukan pengaduan. Wadah atau saluran pengaduan masyarakat tersebut telah diatur dalam Peraturan Menteri Pendayagunaan Aparatur Sipil Negara dan Reformasi Birokrasi Republik Indonesia Nomor 24 Tahun 2014 Tentang Pedoman Penyelenggaraan Pengelolaan Pengaduan Pelayanan Publik secara Nasional. Dalam peraturan menteri tersebut menyebutkan bahwa aduan yang bisa diadukan adalah yang berkaitan dengan pelayanan publik.

Jumlah pengaduan masyarakat berdasarkan hasil data yang ada sejak tahun 2017 sampai tahun 2018 pada DPMPTSP Kota Banjarmasin mengalami kenaikan dimana pada tahun 2017 jumlah aduan masyarakat yang masuk sebanyak 25 aduan. Kebanyakan materi aduan yang disampaikan masyarakat pada tahun 2017 bukan wewenang dari DPMPTSP karena materi aduan bukan terkait masalah keluhan pelayanan yang diterima masyarakat ketika mengurus izin. Sedangkan jumlah pengaduan pada tahun 2018 meningkat menjadi 36 aduan dimana materi aduan yang merupakan wewenang DPMPTSP sebanyak 8 aduan dan 28 aduan yang bukan wewenang DPMPTSP akan di arahkan ke Dinas teknis yang berwenang menangani masalah tersebut. Ini menandakan adanya kenaikan pengaduan masyarakat dari tahun ketahun, akan tetapi kalau dianalisa secara mendalam aduan masyarakat tersebut bukanlah permasalahan yang berkaitan dengan penyelenggaraan pelayanan publik seperti yang diamanatkan dalam Permen PAN-RB RI Nomor 24 tahun 2014 dimana materi aduan yang bisa dilaporkan adalah terkait proses mendapatkan pelayanan publik atau pelayanan pelaksana yang tidak sesuai dengan standar pelayanan, atau mengabaikan kewajiban dan/atau pelanggaran larangan oleh penyelenggara dalam hal ini dalam pengurusan perizinan dan non perizinan.

Untuk menjabarkan dan lebih terarahnya pengelolaan pengaduan pelayanan masyarakat tersebut maka diperlukan adanya suatu mekanisme dan alur penanganan pengaduan yang jelas dan sesuai dengan keadaan serta situasi masyarakat dalam hal ini dituangkan dalam Peraturan Kepala Dinas Penanaman Modal dan Pelayanan Terpadu Satu Pintu Kota Banjarmasin Nomor 29 Tahun 2018 Tentang Mekanisme dan Alur Penanganan Pengaduan Pelayanan Bidang Perizinan dan Non Perizinan Pada Dinas Penanaman Modal dan Pelayanan Terpadu Satu Pintu Kota Banjarmasin.

Penelitian yang dilakukan oleh Prasetya (2013) menunjukkan bahwa ada beberapa kendala yang menghambat proses pengaduan dalam rangka pelayanan publik, mulai dari kurangnya petugas pengelola, berbelitnya birokrasi serta kurangnya sosialisasi kepada masyarakat dalam melakukan penanganan pelayanan. Hal tersebut dikarenakan sosialisasi pemerintah yang kurang serta kurang aktifnya masyarakat dalam mencari informasi. Sedangkan penelitian yang dilakukan oleh Irawan (2017) dengan penekanan terhadap mekanisme penyaluran keluhan, hasil penelitian menunjukkan belum optimalnya mekanisme penyaluran keluhan baik secara langsung maupun tidak, penelitian tersebut juga menunjukkan respon yang belum optimal atas pengaduan masyarakat walaupun sudah ada SOPnya, selain 
itu juga terlihat belum tersedianya sarana pengaduan yang tidak langsung di dalam pelayanan tersebut.

Dari penelitian di atas terlihat bahwa ada beberapa hasil Analisa yang menunjukkan banyak faktor yang mempengaruhi pengelolaan pengaduan terhadap pelayanan yang dilakukan, oleh sebab itulah pentingnya penelitian di Dinas Penanamaan Modal dan Pelayanan terpadu satu pintu di kota Banjarmasin dilakukan dalam menghadapi masyarakat yang semakin pintar dan tahu akan hak-haknya.

Penelitian ini bertujuan untuk 1. Menganalis mekanisme alur pengelolaan pengaduan pada Dinas Penanaman Modal dan Pelayanan Terpadu satu Pintu Kota Banjarmasin, 2. menganalisis mekanisme dan alur pengelolaan pengaduan pelayanan masyarakat sesuai dengan peraturan pemerintah, 3. Mengidentifikasi kendala yang dihadapi dalam pengelolaan pengaduan pelayanan masyarakat.

Menurut Soewarno (1997: 9) pengelolaan juga bisa diartikan penyelenggaraan suatu kegiatan. Pengelolaan bisa diartikan manajemen, yaitu suatu proses kegiatan yang dimulai dari perencanaan, pengorganisasian, pengarahan dan pengawasan usaha-usaha para anggota organisasi dan penggunaan-penggunaan sumber daya organisasi lainnya agar mencapai tujuan organisasi yang telah ditentukan.

Menurut Kepmen PAN Nomor 25 Tahun 2004 yang dimaksud dengan pelayanan adalah segala kegiatan pelayanan yang dilaksanakan oleh penyelenggara pelayanan publik sebagai upaya pemenuhan kebutuhan penerima layanan, maupun dalam rangka pelaksanaan ketentuan peraturan perundang-undangan. Sedangkan Kepmen PAN Nomor 58 Tahun 2002 mengelompokkan tiga pelayanan dari instansi serta BUMN/BUMD. Pengelompokkan jenis pelayanan tersebut didasarkan pada ciri-ciri dan sifat kegiatan serta produk pelayanan yang dihasilkan, yaitu (1) pelayanan administratif, (2) pelayanan barang, (3) pelayanan jasa.

Dinas Penanaman Modal dan Pelayanan Terpadu Satu Pintu Kota Banjarmasin dalam melakukan pelayanan mempunyai standar-standar yang telah ditetapkan sesuai dengan Keputusan Menteri PAN Nomor 63/KEP/M.PAN/7/2003 Tentang Pedoman umum Penyelenggaraan Pelayanan Publik yang mana ada standar terkait prosedur pelayanan; waktu penyelesaian; biaya pelayanan; produk pelayanan; sarana dan prasarana; kompetensi petugas pelayanan.

Penanganan terhadap pengaduan masyarakat adalah suatu yang wajib dilakukan oleh institusi publik, hal ini sejalan dengan pendapat Wales \& Barbour (2010) yang dimuat dalam NSW Ombudsman dengan judul Effective Complaint Handling Guidelines, penanganan keluhan merupakan salah satu komponen penting dalam formula peningkatan kepuasan dan dukungan pengguna layanan publik. Menurut Buku Guide to Complaint handling in Health Care Services (Gorton. et.al. 2005: 2), menyebutkan bahwa: "Complaints are a vital form of consumer feedback that provides unique and valuable information to an organisation concerned with quality improvement and risk management." Pengaduan masyarakat memiliki elemen penanganan pengaduan. Elemen penanganan pengaduan terdiri dari beberapa aspek antara lain:

a. Sumber atau Asal Pengaduan 
b. Isi Pengaduan

c. Unit Penanganan Pengaduan

d. Respon Pengaduan

e. Umpan Balik

f. Laporan Penanganan Pengaduan.

Sebagaimana telah dipaparkan di atas, bahwa tujuan penelitian ini adalah untuk menganalisa mekanisme, alur pengelolaan pengaduan dan mengidentifikasi kendala yang dihadapi dalam pengelolaan pengaduan pelayanan masyarakat. Dari itu, penulis menyusun kerangka berfikir sebagai berikut:

Gambar 1. Kerangka Pikir Penelitian

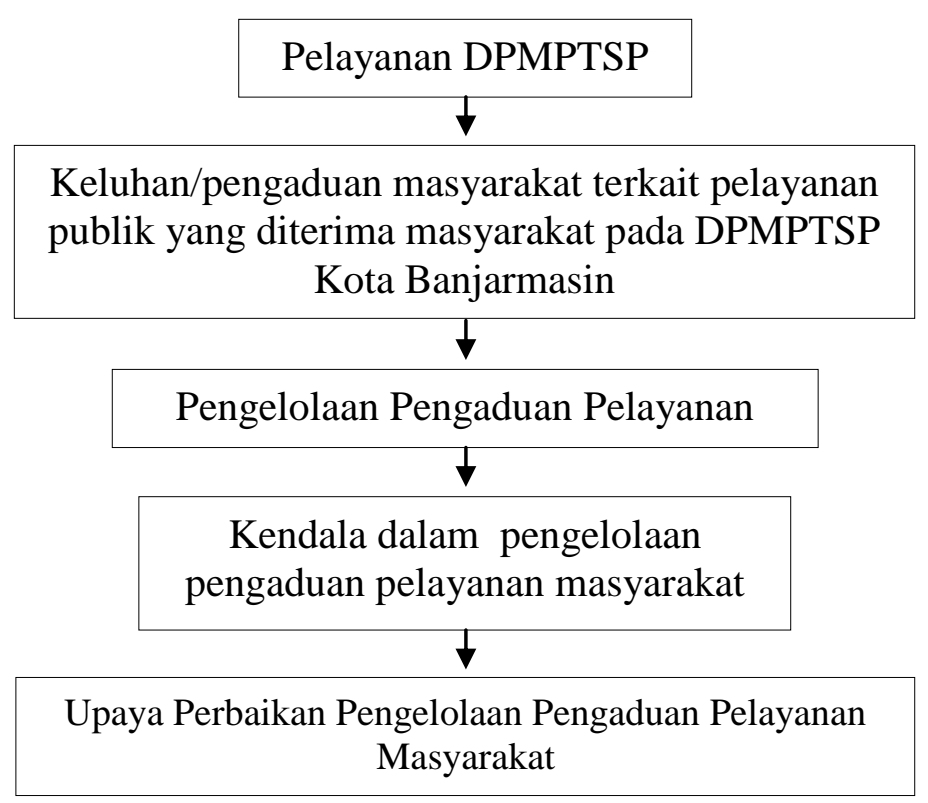

Sumber: diolah dari data primer 2020

\section{METODE PENELITIAN}

Pendekatan penelitian ini bersifat deskriptif kualitatif, yang mendeskripsikan secara terperinci fenomena yang terjadi dalam pengelolaan pengaduan pelayanan masyarakat pada Dinas Penanaman Modal dan Pelayanan Terpadu Satu Pintu Kota Banjarmasin. Data-data diperoleh selain dari sumber informasi yang mengetahui tentang fokus masalah penelitian juga dari sumber informasi kunci untuk mengkonfirmasi terhadap data-data yang diperoleh. Data-data diperoleh dengan melakukan wawancara, observasi dan dokumentasi. Kegiatan pencarian data berhenti apabila data yang diperoleh sudah jenuh.

Teknik analisis data yang digunakan dalam penelitian ini adalah metode non statistik. Hal ini dilakukan karena penelitian ini tidak mencari hubungan antara dua variabel atau lebih. Teknik analisa data dalam penelitian ini adalah mengikuti anjuran Emzir (2011: 129) dengan mengikuti langkah-langkah Miles dan Huberman yang masih bersifat umum yaitu:(1) reduksi data, (2) penyajian atau displai data dan (3) pengambilan kesimpulan/verifikasi. 


\section{HASIL DAN PEMBAHASAN}

\section{Mekanisme dan Alur Pengelolaan Pelayanan Pengaduan}

Mekanisme dan alur pengelolaan pengaduan pelayanan masyarakat pada Dinas Penanaman Modal dan Pelayanan Terpadu Satu Pintu Kota Banjarmasin, melalui data dokumen, dapat disimpulkan bahwa secara umum mekanisme pengaduan pelayanan publik berdasarkan Permen PAN \& RB RI No. 24 Tahun 2014, baik pengaduan langsung maupun pengaduan tidak langsung ada tahapan atau fase yang harus dilalui yakni ada 5 (lima) tahapan yaitu:

\section{Bagan 1. Alur Pengaduan Berdasarkan Permenpan RB RI No 24/2014}

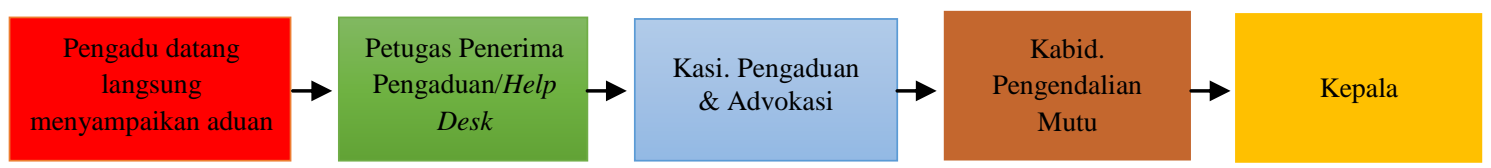

Sumber: Permenpan RB RI, 2014

Hasil penelitian di lapangan terhadap alur dan mekanisme pengaduan tersebut ternyata ada fase atau tahapan yang hilang atau terlewati, hal ini diakibatkan oleh tidak tersedianya tenaga staf pengelola data pengaduan yang menangani/penerima pengaduan atau dengan kata lain tidak tersedianya pegawai staf sehingga fase tersebut terloncati dan langsung diambil alih oleh Kasi pengaduan dan Advokasi.

Bagan 2. Kondisi Riil Aliran Pengaduan

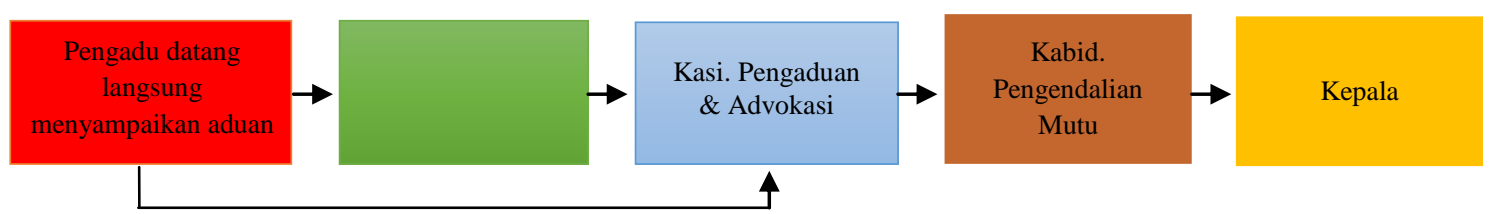

Sumber: diolah dari hasil penelitian, 2020

Hasil kajian menunjukkan, melalui perbandingan antara data dokumen tentang Mekanisme dan Alur Pengelolaan Pengaduan Masyarakat menurut Permen PAN\&RB RI Nomor 24 Tahun 2014 Tentang Pedoman Penyelenggaraan Pengelolaan Pengaduan Pelayanan Publik secara Nasional dengan data hasil wawancara tentang mekanisme dan alur yang berlangsung saat ini ternyata ada sedikit perbedaan, dimana dalam prakteknya ternyata ada tahapan yang tidak terlaksana, yaitu Tahap Penerimaan Pengaduan Oleh Petugas (Help Desk) tidak tersedia sesuai tuntutan Peraturan tersebut. 


\section{Kesesuaian Pengelolaan Pengaduan Pelayanan dengan Mekanisme dan Alur}

Pelaksanaan pengelolaan pengaduan pelayanan masyarakat pada Dinas PMPTSP Kota Banjarmasin memang sudah terlaksana seperti yang diamanatkan oleh Permen PAN \& RB RI Nomor 24 Tahun 2014, tetapi dari segi operasionalnya belum secara optimal, ini dapat dilihat baik dari segi kualitas pelayanan dimana ada saja masyarakat yang masih mengeluh terhadap pelayanan yang dilakukan seperti keramahan petugas pelayanan, ketepatan dan kecepatan waktu penyelesaian. Dari segi kuantitas aduan yang masuk selama tahun 2019 mulai dari Januari sampai Desember sebanyak 55 aduan dan konsultasi masyarakat yang masuk baik secara lisan, tertulis maupun melalui SP4N LAPOR!.

Walaupun materi aduan yang masuk kebanyakan bukan wewenang dari Dinas PMPTSP Kota Banjarmasin, hal ini tentunya menandakan bahwa masih tingginya ketidaktahuan masyarakat terhadap pengelolaan penanganan pengaduan pelayanan masyarakat di Dinas PMPTSP Kota Banjarmasin yang disebabkan oleh kurangnya sosialisasi yang dilakukan oleh Dinas PMPTSP Kota Banjarmasin kepada masyarakat terkait materi aduan yang bisa dilayani oleh Seksi pengaduan dan advokasi yang ada pada Dinas PMPTSP Kota Banjarmasin.

\section{Kendala Dalam Pengelolaan Pengaduan Pelayanan Masyarakat}

Hasil pengamatan dan penelitian menunjukkan bahwa ada beberapa faktor yang menyebabkan tidak optimalnya pelaksanan Mekanisme dan Alur pengelolaan pengaduan masyarakat pada Dinas Penanaman Modal dan Pelayanan Terpadu Satu Pintu Kota Banjarmasin. Kendala yang dihadapi ini, peneliti menyimpulkan ke dalam 2 (dua) faktor, sebagaimana bagan berikut:

\section{Bagan 3. Kendala Pengelolaan Pengaduan Pelayanan}

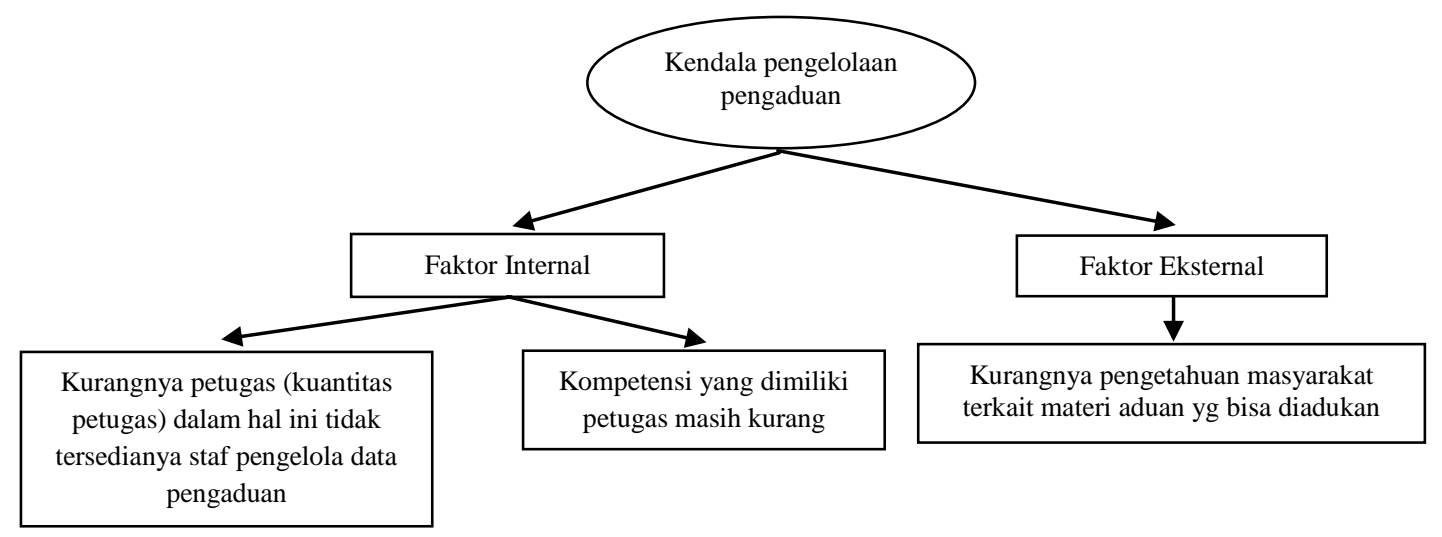

Sumber: diolah dari hasil penelitian, 2020

\section{PENUTUP}

Hasil penelitian ini menyimpulkan ada perbedaan yang terjadi pada mekanisme dan alur pengelolaan pengaduan pelayanan masyarakat pada Dinas Penanaman Modal dan Pelayanan Terpadu Satu Pintu Kota Banjarmasin, antara yang seharusnya sesuai Permen PAN-RB dengan yang berjalan atau dilaksanakan saat ini, dimana dalam prakteknya baik pengaduan 
secara langsung maupun tidak langsung ada satu tahapan yang terlewati atau tidak terlaksana karena tidak adanya petugas penerima pengaduan/help desk.

Implementasi Mekanisme dan Alur dalam Pengelolaan Pengaduan Pelayanan Masyarakat pada Dinas Penanaman Modal dan Pelayanan Terpadu Satu Pintu Kota Banjarmasin yang dikelola oleh bidang Pengendalian Mutu unit teknis Seksi Pengaduan dan Advokasi tidak sesuai dengan mekanisme dan alur yang telah diatur dalam Peraturan Menteri Pendayagunaan Aparatur Sipil Negara dan Reformasi Birokrasi Republik Indonesia Nomor 24 Tahun 2014 Tentang Pedoman Penyelenggaraan Pengelolaan Pengaduan Pelayanan Publik secara Nasional, dikarenakan belum optimal terutama yang berkaitan dengan esensi pengelolaan pengaduan pelayanan yang diberikan karena masih kurangnya pemahaman masyarakat tentang tupoksi dari Dinas PMPTSP Kota Banjarmasin.

Kendala dalam dalam pengelolaan pengaduan pelayanan dari Dinas PMPTSP ada dua yaitu; faktor Internal yaitu kurangnya tenaga staf, sert kompetensi petugas belum sesuai seperti yang diharapkan. Sedangkan untuk faktor eksternalnya adalah kurangnya pengetahuan masyarakat terkait materi pengaduan apa saja yang bisa diadukan pada pengelolaan pengaduan pelayanan masyarakat sehingga tugas Dinas PMPTSP bertambah dengan menyalurkan pengaduan kepada dinas-dinas yang yang dikeluhkan.

Saran yang dapat peneliti rekomendasikan adalah melakukan optimalisasi Mekanisme dan alur pengelolaan pengaduan pelayanan yang sudah ada sehingga dalam proses pengelolaannya tidak memakan waktu yang lama. Dari segi dokumen, mekanisme yang ada perlu disederhanakan lagi karena birokrasi yang memakan waktu cukup lama. Untuk penempatan pegawai, terutama ASN agar sebelum ditempatkan pada jabatan tertentu perlu diadakan pendidikan dan pelatihan sehingga lebih menguasai. Kepada Dinas Penanaman Modal dan Pelayanan Terpadu Satu Pintu Kota Banjarmasin Agar lebih mengintensifkan sosialisasi kepada masyarakat terkait pengelolaan pengaduan pelayanan masyarakat yang berhubungan dengan Pengurusan Perizinan dan Non Perizinan. Berdasarkan hasil temuan terhadap kesalahan opini masyarakat terhadap penamaan (Nomenklatur) Dinas Penanaman Modal dan Pelayanan Terpadu Satu Pintu perlu dikaji ulang kembali dengan kata lain menyederhanakan dan dipertegas nama dinas ini sehingga jelas dan mudah dipahami oleh masyarakat.

\section{DAFTAR PUSTAKA}

Emzir. (2011). Analisis data: metodologi penelitian kualitatif. Jakarta: Rajawali Pers.

Gorton, M. dkk. 2005. Health Service Review Council: Guide to Complaint Handling in Health Care Services. Australia.

Irawan, B. (2017). Analisis Pelaksanaan Pengaduan Masyarakat Di Kantor Samsat Kota Samarinda. Jurnal Administrative Reform (JAR), 5(1), 1-14.

Keputusan Menteri Pendayagunaan Aparatur Negara No. 58 Tahun 2002 tentang Pedoman Pelaksanaan Penilaian dan Penghargaan Citra Pelayanan Prima Sebagai Unit Pelayanan Percontohan. 
ISSN 2088-7469 (Paper) ISSN 2407-6864 (Online)

Volume 10 Nomor 2 (2020)

Keputusan Menteri Pendayagunaan Aparatur Negara Nomor 25 Tahun 2004 tentang Pedoman Umum Penyusunan Indeks Kepuasan Masyarakat Unit Pelayanan Instansi Pemerintah

Keputusan Menteri Pendayagunaan Aparatur Negara Nomor 63 Tahun 2003 tentang Pedoman Umum Penyelenggaraan Pelayanan Publik.

Peraturan Kepala DPMPTSP Kota Banjarmasin No.29 Tahun 2018 tentang Mekanisme dan Alur Penanganan Pengaduan Pelayanan Bidang Perizinan dan Non Perizinan pada Dinas Penanaman Modal dan Pelayanan Terpadu Satu Pintu kota Banjarmasin.

Peraturan Menteri Pendayagunaan Aparatur Negara dan Reformasi Birokrasi RI No. 24 Tahun 2014 tentang Pedoman Penyelenggaraan Pengelolaan Pengaduan.

Prasetya, D. R. (2013). Analisis Pengelolaan Pengaduan Masyarakat Dalam Rangka Pelayanan Publik (Studi Pada Dinas Komunikasi Dan Informatika Kota Malang). Jurnal Administrasi Publik, 1(6), 1151-1158.

Soewarno, H. (1997). Pengantar Studi Ilmu Administrasi dan Manajemen. Jakarta: CV Haji Masagung. 